\title{
A modelling system for estimating freight quantities attracted by cities
}

\author{
A. Comi \& E. Conte \\ Department of Civil Engineering, Tor Vergata University of Rome, Italy
}

\begin{abstract}
The paper proposes the calibration of a modelling system that allows us to simulate the end-consumer mobility in order to obtain the freight quantities attracted for satisfying their needs, also disaggregated for freight types. The models were developed using the results of various surveys carried out in a suburb in the city of Rome where more than 200 households were interviewed. The shopping journeys, considering both home-based trips and non home-based trips (e.g. home-work-shopping-work-home), have been pointed out. Different models have been calibrated in relation to different aggregation levels of freight types and end-consumers.

Keywords: urban goods movements, attraction models, transport demand model, city logistics.
\end{abstract}

\section{Introduction}

In the sphere of sustainability, many cities around the world have implemented different types of measures in order to reduce the impacts of freight transport. Consequently, identification and classification of implementable measures, and models for the simulation of different scenarios are required for their assessment.

As demonstrated by several studies [1, 2], freight mainly reaches cities to satisfy the end-consumer's demand. Consequently, urban freight transport is mainly the result of restocking of retail activities. In literature, some models have been developed to simulate aspects of the restocking process without starting from the end-consumer demand. Others treat goods movements starting from consumer needs and/or from her/his activities.

In the ex-ante assessment of city logistics scenario, considering these interactions between goods and passenger/person movements is crucial because 
commodity flows don't take place on their own dedicated network, but they share the transport infrastructure with passenger ones. Then, Russo and Comi [3] have proposed a modelling framework that explicitly represents these relationships. They have assumed that commodity flows are generated by the consumption of a commodity, as part of the conduct of a given, generic urban activity undertaken by end-consumers. The main characteristic of this model is the representation of interacting behaviour of commodity consumers and commodity suppliers/shippers/retailers.

In this background, the paper recalls the general framework proposed by Russo and Comi [3] and proposes the calibration of models that allow us to simulate the end-consumer mobility in order to obtain the freight quantities required in the study area, also disaggregated for freight and end-consumers types.

In the following, the paper provides a review of mainly studies developed in order to identify and classify the implementable measures and models (section 2). Then, the section 3 recalls the modelling architecture for simulating urban goods movements in an integrated way; section 4 gives the results of calibration for a suburb of Rome. Finally, some conclusions are given in section 5.

\section{The state-of-the-art}

\subsection{City logistics measures}

An initial list of measures related to urban freight transport was given by COST 321 [4]. About 60 measures were identified and classified into eight different classes. COST 321 provided quantitative results on the impacts of measures and estimated effects in projects and case studies. Following the COST 321 results, in 2000 the European Commission established a thematic network on Best Urban Freight Solutions (BESTUFS) with a 4-year duration. BESTUFS aimed to identify and disseminate best practices with respect to urban freight transport $[5,6]$.

In the same period, the European Commission also supported the project City Ports [7] in order to investigate tools and policies for urban goods distribution used in some European cities. This project drew up a general method to address city logistics within a comprehensive framework where policies are defined after local analysis, ranking of critical issues, design and evaluation of specific solutions, and through the involvement of the various stakeholders.

Finally, from 2002 the European Commission have been supporting CIVITAS Initiative (CIty-VITAlity-Sustainability - cleaner and better transport in cities) in order to generate a decisive breakthrough by supporting and evaluating the implementation of ambitious integrated sustainable urban transport strategies that should make a real difference for the welfare of the European citizen [8]. In particular, in the cities involved in the ELAN project (within the last edition of CIVITAS), solutions related to improve urban freight distribution have been studying: test of a combination of innovative measures in 
the field of limiting access and consolidated deliveries, as well as introducing of appropriate incentives for cleaner freight traffic.

In the last years, much attention has been paid on Urban Distribution Centre (UDC) or Urban Consolidation Centre (UCC): logistic terminals (multi-company distribution centres) for transhipment from long-distance to short-distance (urban) traffic where consignments can be sorted and bundled. They have been proposed to alleviate traffic congestion and reduce environmental, energy and labor costs [9]. In order to identify the potential for the development of urban consolidation centres, in the United Kingdom the Department of Transport commissioned the Transport Studies Group of the University of Westminster to analyse the advantages and disadvantages, and the impact on transport operations and on other supply chain activities, caused by the Urban Consolidation Centres [10]. Recently, work was carried out to investigate how transport decisions are made by receivers or by transport operators regarding the potential use of an urban freight consolidation centre in the city of Fano (Italy), and the results of a stated-preference study were reported. Simulations were performed to assess how the potential demand is affected by various incentives and regulations affecting urban goods distribution [11].

Munuzuri et al. [12] have proposed a list of solutions or initiatives that could be implemented by local administrators in order to improve urban freight transport. Their analysis is done from the point of view of urban communities. They propose to classify the measures in five classes: public infrastructure, land use management, access conditions, traffic management, enforcement and promotion.

Van Duin and Quak [13] have identified three main areas of attention in city logistics: flow improvements (including cooperation between companies, consolidation centres, transport reorganizing and routing improvements), hardware (including infrastructure, parking and unloading facilities) and policy (including licensing and regulation).

Finally, addressing by the need to identify homogeneous characteristics that allow to highlight who must take decisions (public authority, private company, public-private partnership), who has to abide by them (e.g. end-consumer, receiver, shipper, wholesaler) or which links of logistics system are involved (producer-wholesaler, wholesaler-retailer, producer-retailer) Russo and Comi [6] have proposed a classification that allows us to take into account the involved actors, the planning horizons and connected impacts.

\subsection{Models for urban goods movement simulations}

Several methods and models have been developed in order to assess ex-ante the results to be achieved by the implementation of city logistics measures [14]. Most models have been developed within the sequential modelling approach by considering three different categories, based respectively on: trucks [15-17], commodities/quantities $[3,15,18]$ and deliveries $[19,20]$. However, we find few studies treating the overall problem of urban freight transport simulation. Existing models mainly simulate some aspects of the restocking process and, in particular, relate to inter-urban freight movements. Few of them consider the 
possibility of combining freight and passenger flows [18], hence of representing the interacting behaviour of commodity consumers and commodity suppliers/shippers/retailers. Thus, there are difficulties forecasting the impact and simulating the effects of transportation measures on an urban scale. The endconsumer movements are mainly studied within the passenger mobility and few studies have considered them belonging to urban freight distribution as a part of the supply chain [21-23]. There are models that treat goods movements starting from consumer needs and/or from her/his activities (e.g. purchase demand example of a joint/direct model: 18; example of a partial share model: 3 ), and models that treat goods movements independently of others. In this respect, models may be integrated or non-integrated with passenger/personal transportation models. Some authors have also proposed general modelling framework that can be considered as open architecture. As proposed by Russo and Comi [3], it is possible to introduce specific models from current literature that allow to take into account the impact due to the city logistics measures implementation on end-consumer goods demand and restocking process of urban retail businesses. Within the modelling architecture proposed by Russo and Comi [3], the freight attracted by study area in order to satisfy the end-consumers' demand is estimated analysing the end-consumer journeys (i.e. shopping journeys): simulation of $o-d$ trip for shopping/purchasing and simulation of purchased goods quantity. Referring to the former the proposed models mainly consider round trips and two types of purchases: durable and non-durable goods [24]. The latter ones are mainly aggregate and consider only one freight type [22].

In this context, the general framework as proposed by Russo and Comi [3] is recalled in the following section and, then, the models that allow us to simulate the end-consumer mobility in order to obtain the freight quantities required within urban and metropolitan area are developed. The models were set up using the results of some surveys carried out in a suburb in the city of Rome where more than 200 households were interviewed. Different models have been calibrated in relation to different aggregation level of freight and category of end-consumer.

\section{The modelling architecture}

\subsection{The general model}

The modelling architecture proposed by Russo and Comi [3] allows us to combine consumer trips and goods movements at an urban and metropolitan scale. It is developed on two levels, concerns a medium-size city, and applies a disaggregated approach for each decisional level (Figure 1):

- commodity level (first level) concerning the estimation of quantity flows; at this level the models concern calculation of the demand by freight type, by $o-d$ consumption pair and $d-W / Z$ restocking pair;

- vehicle level (second level) that allows quantity flows to be converted to vehicle flows; at this level the models concern determination of the 


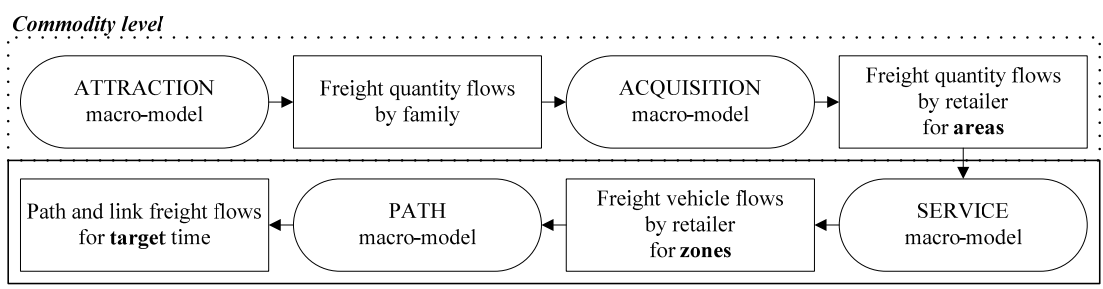

Vehicle level

Figure 1: $\quad$ Modeling architecture.

service, vehicle and time used as well as the path chosen for restocking sales outlets.

In the attraction macro-model the decision-maker is identified with the endconsumer (e.g. family). It allows us to calculate the freight quantities (disaggregated by freight type) that are consumed in a zone $o$ (within the study area) and purchased (thus required/attracted) in a zone $d$ (within the study area). The acquisition macro-model allows us to know whether the freight for restocking arrives from inside or outside the study area. With the service macromodel the restocking journey may be analyzed in terms of number of stops per trip and size and stock zone. Finally, the path macro-model gives us the target time and path used.

\subsection{The attraction macro-model}

The attraction macro-model consists of a set of elementary models that allow us to calculate the goods quantity (disaggregated for freight types) required within the urban and metropolitan area to satisfy the end-consumers' needs. The total quantity of freight type $s$ attracted from zone $d, Q_{S, t o t, d}$, can be calculated as [3]:

$$
\begin{aligned}
Q_{s, t o t, d} & =Q_{s, d}+Q E_{s, d}=\sum_{o} Q_{s, o d}+Q E_{s, d}=\sum_{d i m} \sum_{o} T R I P_{s, o d}(\operatorname{dim}) \cdot \operatorname{dim}+Q E_{s, d}= \\
& =\sum_{\operatorname{dim}} \sum_{o} T R I P_{s, o} \cdot p[d / o s] \cdot p[\operatorname{dim} / \operatorname{dos}] \cdot \operatorname{dim}+Q E_{s, d}
\end{aligned}
$$

where

- $Q_{s, d}$ is the goods quantity bought/sold in $d$ given by the demand of endconsumers living/working in a zone $o$ within the study area;

- $Q E_{s, d}$ is the goods quantity bought/sold in $d$ given by the demand of end-consumers living/working in a zone $z$ external to the study area;

- $Q_{s, o d}$ is the goods quantity bought in zone $d$ by end-consumers living/working in zone $o$ (sold by retailers of zone $d$ );

- $\quad T R I P_{s, o}$ is the number of trips for purchase of freight type $s$ with origin in the inner zone $o$;

- $T R I P_{s, o d}(\mathrm{dim})$ is the number of trips for purchases of freight of type $s$, from $o$ to $d$, concluding with a purchase of dimension dim; 
- $\quad \operatorname{dim}$ is the dimension of purchases;

- $\quad p[d / o s]$ is the probability of trips being undertaken by end-consumer $E$ going to destination $d$ conditional upon leaving from $o$ for purchases of type $s$; it is estimated by a distribution model;

- $\quad p[\mathrm{dim} / \mathrm{dos}]$ is the probability to conclude a trip with a purchase of dimension $\operatorname{dim}\left(0, \operatorname{dim}_{1}, \operatorname{dim}_{2}, \ldots ., \operatorname{dim}_{n}\right)$ conditional upon undertaking a trip from zone $o$ to zone $d$ for a purchase of goods type $s$; it is estimated by a dimension choice model.

\section{Specification and calibration}

\subsection{The dataset}

In order to specify and calibrate the models within the attraction macro-model some surveys have been carried out in a suburb of Rome (project area).

The whole area of the municipality of Rome has been divided into a finite number of discrete traffic zones (as customary in traffic studies, see 24). Traffic zones are obtained as aggregation of census sections. This allows us to associate to each zone the relevant statistical data (population, employment, etc.) available for such areas. The municipality area has been divided into 99 traffic zones with a level of detail which increases as the project area is approached. The study area has an extension of about $556 \mathrm{~km}^{2}$ has about 86,000 employees related to trade (7,920 related to foodstuffs, 8,950 to household and personal hygiene and 68,974 to other freight types).

The focus of the analysis is on the passenger mobility for shopping. The survey consists of interviews to end-consumers living in a suburb of Rome (i.e. $6^{\text {th }}$ Municipio - Villa Gordiani) in order to obtain information about their weekly shopping journeys. 200 end-consumers have been interviewed. The questionnaire is composed of 3 sections as follows:

1. general information; in this section data on socio-economic characteristics of interviewed (e.g. occupation, age, household size, gender, income and location of residence);

2. characteristics of shopping journey, this section has allowed us to investigate the type of journey (i.e. round trips or trip-chain), and the travel decisions (i.e. frequency, preferred day, timing, destination, transport mode, number of visited shops);

3. characteristics of purchased goods, this section has allowed to investigate the purchases made (i.e. freight type, quantity).

Referring to characteristics of end-consumers, it emerges that about $35 \%$ of interviewees have a high income (more than 40,000 €/year), 52\% are employees and $50 \%$ less than 40 years old. The analysis of the interviews has allowed us to identify the relevant attributes characterising the choice dimensions that have been used in the models:

- old, dummy variable equal to 1 if the end-consumer is older than 40 years, 0 otherwise; 
- $\quad$ num, dummy variable equal to 1 if the household has more than 2 members, 0 otherwise;

- $r c$, dummy variable equal to 1 if the end-consumer's income is more than $40,000 € /$ years, 0 otherwise;

- $w m$, dummy variable equal to 1 if the end-consumer is a woman, 0 otherwise;

- emp, dummy variable equal to 1 if the end-consumer's is employed, 0 otherwise.

\subsection{The generation models}

The number of trips for purchases of freight type $s$ with origin in the zone $o$, $T R I P_{s, o}$, can be estimated as:

$$
T R I P_{s, o}=n(o) \cdot m(o s) \quad[\text { trips } / \text { week }]
$$

where $m(o s)$ is the mean number of trips undertaken to purchase goods of type $s$ departing from $o$, and can be expressed as a linear function of variables, $X_{j o}^{s}$ :

$$
m(o s)=\sum_{j} \beta_{j}^{s} \cdot X_{j o}^{s}
$$

In the literature there are several classifications, albeit developed mainly for analysing the passenger mobility or the freight transport at a wide scale (e.g. national or regional). The classification that gives the best results, in Rome, in simulating restocking of retail activities is the following [25]: foodstuffs, home accessories, stationery, clothing, household and personal hygiene and other. Table 1 reports the values of $\beta_{j}^{s}$ estimated for the case study.

\begin{tabular}{|c|c|c|c|c|c|c|c|}
\hline \multirow[t]{2}{*}{ Attribute } & & \multicolumn{6}{|c|}{ Freight types } \\
\hline & & foodstuffs & $\begin{array}{c}\text { home } \\
\text { accessories }\end{array}$ & stationery & clothing & $\begin{array}{c}\text { household } \\
\text { and } \\
\text { personal } \\
\text { hygiene }\end{array}$ & other \\
\hline Age (old) & $\beta_{\text {old }}$ & $\begin{array}{l}0.593 \\
(4.26) \\
\end{array}$ & & & & $\begin{array}{l}0.076 \\
(2.10) \\
\end{array}$ & \\
\hline $\begin{array}{c}\text { Family } \\
\text { components (num) }\end{array}$ & $\beta_{\text {mum }}$ & $\begin{array}{l}0.531 \\
(4.40) \\
\end{array}$ & $\begin{array}{l}0.096 \\
(3.34) \\
\end{array}$ & & $\begin{array}{l}0.120 \\
(2.58) \\
\end{array}$ & & $\begin{array}{l}0.102 \\
(5.06) \\
\end{array}$ \\
\hline $\begin{array}{c}\text { End-consumer's } \\
\text { income }(r c)\end{array}$ & $\beta_{r c}$ & $\begin{array}{l}0.381 \\
(2.52)\end{array}$ & & $\begin{array}{l}0.146 \\
(3.46)\end{array}$ & & & $\begin{array}{l}0.053 \\
(2.00)\end{array}$ \\
\hline $\begin{array}{l}\text { End-consumer's } \\
\text { gender }(w m)\end{array}$ & $\beta_{w m}$ & $\begin{array}{l}0.179 \\
(1.33) \\
\end{array}$ & & $\begin{array}{l}0.096 \\
(2.63) \\
\end{array}$ & $\begin{array}{l}0.076 \\
(1.41) \\
\end{array}$ & $\begin{array}{l}0.126 \\
(3.76) \\
\end{array}$ & $\begin{array}{l}0.051 \\
(2.29) \\
\end{array}$ \\
\hline $\begin{array}{l}\text { End-consumer's } \\
\text { job (emp) }\end{array}$ & $\beta_{e m p}$ & & $\begin{array}{l}0.045 \\
(1.34)\end{array}$ & $\begin{array}{l}0.118 \\
(3.24)\end{array}$ & & $\begin{array}{l}0.083 \\
(2.97)\end{array}$ & \\
\hline$\rho^{2}$ & & 0.64 & 0.39 & 0.36 & 0.18 & 0.50 & 0.45 \\
\hline
\end{tabular}

Table 1: Generation model: calibration results.

The obtained results are all significant as demonstrated by $t$-ratio and $\rho^{2}$.The results show that components of large family and females undertake more than one trip for week. It also happens for worker with high income. The trips for 
purchasing foodstuffs, and household and personal hygiene products (i.e. daily consumption products) are strictly dependent on age of end-consumers. In fact, as confirmed by surveys, the older people usually undertake more trips per week to purchases these types of goods.

\subsection{The distribution models}

The second elementary model is the distribution model through which the number of trips to $d$ from $o$ are obtained.

All the following models are Random Utility Models and were specified assuming that the random residuals are i.i.d. $(\varepsilon)$ as a Gumbel variable. Under this hypothesis the probability can be calculated by a multinomial logit model where the systematic utility, $V$, can be expressed as a linear function of some attributes, $X_{i}$ :

$$
\mathrm{V}=\sum_{\mathrm{i}} \beta_{\mathrm{i}} \mathrm{X}_{\mathrm{i}}
$$

The probability, $p[d / o s]$, can be estimated by a gravitational model as:

$$
p[d / o s]=E P_{s, d}^{\beta_{1}^{s}} \cdot \exp \left(\beta_{2}^{s} \cdot C_{o d}\right) / \sum_{d^{\prime}}\left[E P_{s, d^{\prime}}^{\beta_{1}^{s}} \cdot \exp \left(\beta_{2}^{s} \cdot C_{o d^{\prime}}\right)\right]
$$

where

- $E P_{s, d}$ is the number of retail trade employees in zone $d$ for freight type $s$,

- $C_{o d}$, is the distance between zone $o$ and $d$, calculated on the road network according to the path of minimum generalised travel cost, expressed in $\mathrm{km}$;

- $\quad \beta_{1}^{s}$ and $\beta_{2}^{s}$ are the calibrated model parameters reported in Table 2.

\begin{tabular}{|c|c|c|c|}
\hline \multirow[t]{2}{*}{ Attribute } & & \multicolumn{2}{|c|}{ Freight types } \\
\hline & & non-durable goods & durable goods \\
\hline & & foodstuffs & $\begin{array}{l}\text { home accessories, stationery, clothing, } \\
\text { household and personal hygiene, other }\end{array}$ \\
\hline $\begin{array}{c}\text { Employees } \\
\left(E P_{d}\right)\end{array}$ & $\beta_{1}$ & 0.025 & 0.118 \\
\hline $\begin{array}{c}\text { Distance } \\
\left(C_{o d}\right)\end{array}$ & $\beta_{2}$ & -3.236 & -2.152 \\
\hline$\rho^{2}$ & & 0.53 & 0.29 \\
\hline
\end{tabular}

Table 2: Distribution model: calibration results.

Even if distribution models have been calibrated both for all the six identified freight types, similar results have been obtained for the freight types that belong to durable and non-durable goods types. For this reason, Table 2 reports two sets of parameters to be used for both durable and non-durable goods. All parameters are correct in sign and are statistically significant as shown by values of $\rho^{2}$ that are similar to those present in literature for models of this type. By analyzing results of Table 2 it is possible to point out that the number of employees plays more for durable goods, while the weight of distance works the same way. It should be noted that the traffic zone $d$ is a compound alternative composed of the 
aggregation of elementary alternatives. Further analysis has been developing in order to calibrate others models considering the size function as proposed by Ben-Akiva and Lerman [26] and Cascetta [24].

\subsection{The dimension choice models}

Having obtained the $o-d$ matrices, in trips, a new model must be introduced that allows a dimension to be given to each trip. This model is the dimension choice model.

It should be noted that the end-consumer arriving in a zone, can or not purchase. Thus, an intermediate model has been included in the general framework in order to estimate the probability to buy or not. The probability to purchase has been estimated by a binomial logit model:

$$
p[\text { purchase } / d o]=\exp \left(V_{\text {purchase }}\right) /\left[\exp \left(V_{\text {purchase }}\right)+\exp \left(V_{\text {no purchase }}\right)\right]
$$

where the systematic utility to purchase, $V_{\text {purchase }}$, has been expressed as linear function of attributes related to socio-economic characteristics of end-consumer. The Table 3 reports the calibration results. All parameters are correct in sign. The value of $\rho^{2}$ is low but it is similar to those present in literature for models of this type. As we had expected, the young or female or employed end-consumers tend to purchase less. Further analyses are in progress in order to improve these first results including some variables related to selling location and endconsumer's income.

Table 3: Purchase model: calibration results.

\begin{tabular}{cccccc}
\hline & $\begin{array}{c}\text { Age } \\
(\text { old })\end{array}$ & $\begin{array}{c}\text { Family } \\
\text { components } \\
(\text { num })\end{array}$ & $\begin{array}{c}\text { Gender } \\
(\text { wm })\end{array}$ & $\begin{array}{c}\text { End- } \\
\text { consumer's } \\
\text { job } \\
(\text { emp })\end{array}$ & ASA \\
\hline Alternative & purchase & purchase & purchase & purchase & no purchase \\
\hline \multirow{2}{*}{ Value $(\beta)$} & -0.516 & -0.458 & -0.295 & -0.418 & -4.113 \\
& $(-1.44)$ & $(-1.77)$ & $(-1.60)$ & $(-2.02)$ & $(-2.20)$ \\
\hline$\rho^{2}$ & & & $\mathbf{0 . 1 9}$ & & \\
\hline
\end{tabular}

Moving on to the dimension choice model, the probability of making a purchase of freight type $s$ of dimension $\operatorname{dim}, p[\mathrm{dim} / \mathrm{dos}]$, can be expressed as:

$$
p[\operatorname{dim} / \operatorname{dos}]=\exp \left(V_{\operatorname{dim}}^{s}\right) / \sum_{m=\operatorname{dim}_{I} \ldots \ldots \operatorname{dim}_{n}} \exp \left(V_{\operatorname{dim}}^{s}\right)
$$

where $V_{d i m}$ is the systematic utility associated to make purchase of dimension $\mathrm{dim}$. The Table 4 reports two sets of calibration results: non-durable and durable goods. The two calibrated models provide three different dimension classes (alternatives), identified as reported in Table 4. The dimension choice model simulates the dimension of purchase made on each journey. We can see that all parameters have the expected signs. Parameter analysis shows the important role of the age for durable goods; in fact, we can see that by increasing the age, the dimension of the purchases increases. It confirms that the old end-consumers 
prefer to buy more than younger ones. The same happens for female and endconsumer belonging to a large family. If end-consumers travel to zone with high number of employees (i.e. shopping area), the probability to buy more increases. Finally, as expected, the negative signs of parameters related to travelled distance confirm that when the distance from residence to destination zone increases, the probability to make big purchases also increases. Finally, referring to income, the results confirm that high income end-consumers prefer to make big purchases.

Table 4: Dimension choice model: calibration results.

\begin{tabular}{|c|c|c|c|c|c|c|c|}
\hline \multirow[t]{3}{*}{ Attribute } & \multirow[t]{3}{*}{ Parameter } & \multicolumn{3}{|c|}{ Alternatives } & \multicolumn{3}{|c|}{ Alternatives } \\
\hline & & \multicolumn{3}{|c|}{ non-durable } & \multicolumn{3}{|c|}{ durable } \\
\hline & & $\operatorname{dim}_{1}$ & $\operatorname{dim}_{2}$ & $\operatorname{dim}_{3}$ & $\operatorname{dim}_{1}$ & $\operatorname{dim}_{2}$ & $\operatorname{dim}_{3}$ \\
\hline $\begin{array}{l}\text { Dimension } \\
{[\mathrm{kg} / \text { week }]}\end{array}$ & & $(0-10]$ & $(10-30]$ & $>30$ & $(0-5]$ & $(5-20]$ & $>20$ \\
\hline Age (old) & $\beta_{\text {old }}$ & & 0.823 & 1.519 & & 0.274 & 0.457 \\
\hline $\begin{array}{c}\text { Family } \\
\text { components } \\
\text { (num) }\end{array}$ & $\beta_{\text {num }}$ & & & 0.730 & & & 0.294 \\
\hline $\begin{array}{c}\text { End- } \\
\text { consumer's } \\
\text { income }(r c)\end{array}$ & $\beta_{r c}$ & & 0.327 & 0.911 & & 0.088 & \\
\hline $\begin{array}{c}\text { End- } \\
\text { consumer's } \\
\text { gender }(w m)\end{array}$ & $\beta_{w m}$ & & 0.140 & & & 0.351 & \\
\hline $\begin{array}{c}\text { Distance } o-d \\
\left(C_{o d}\right)\end{array}$ & $\beta_{c}$ & & & 0.286 & & & \\
\hline $\begin{array}{c}\text { Employees } \\
\left(E P_{d}\right)\end{array}$ & $\beta_{e p}$ & & 0.094 & & & 0.076 & 0.159 \\
\hline ASA & $\beta_{a s a}$ & 4.077 & 2.938 & & 2.034 & 0.961 & \\
\hline$\rho^{2}$ & & & 0.18 & & & 0.12 & \\
\hline
\end{tabular}

\section{Conclusions}

This paper has presented a modelling system for simulating urban mobility for shopping in order to estimate the freight quantities requires by urban and metropolitan areas. It consists of four models developed within the general framework proposed by Russo and Comi [3]: generation, distribution, purchase and dimension choice models. The first two allow us to estimate the OriginDestination matrices for shopping scope. Then, the latter two allow us to give a dimension to each journey undertaken. A dataset of urban freight data collected in the city of Rome has been used to support the model specification and calibration. In particular, the calibration pointed out the key role of the characteristics of end-consumer (age, gender, income, etc.) and the characteristics of destination, for which long trips push end-consumers to make large purchases.

Thus, in the sphere of sustainability where most cities have to deal with the large number of trucks and vans delivering goods in the urban area while 
preserving the economic sustainability of the businesses located in the city and, at the same time, the environmental quality. This macro-model allows us to investigate how urban policies modifying the transportation attributes for passenger (end-consumer) or the sale network can modify the end-consumer demand and thus, the attracted goods quantity.

Other analyses are required in order to obtain more disaggregated models and improve the first results reported in this paper.

\section{Acknowledgement}

The authors wish to thank Prof. Francesco Russo for his valuable comments and suggestions.

\section{References}

[1] Russo, F. and Comi, A. (2011). A Model System For The Ex-Ante Assessment Of City Logistics Measures. Research in Transportation Economics, DOI:10.1016/j.retrec.2010.11.011, Elsevier Ltd.

[2] Nuzzolo, A., Crisalli, U. and Comi, A. (2008). Metropolitan freight distribution by railways. Innovations in City Logistics, E. Taniguchi and R. G. Thompson (eds.), Nova Science Publishers, Hauppauge NY, U.S.A..

[3] Russo, F. and Comi, A. (2010). A modelling system to simulate goods movements at an urban scale. Transportation 37 (6), Springer Science+Business Media, LLC.

[4] COST 321 (1998). Urban goods transport, Final report of the action. Transport Research, European Commission Directorate General Transport, Belgium.

[5] Wild, D. (2003). The BESTUFS project. Proceedings of 4th BESTUFS Conference, Prague, Czech Republic.

[6] Russo, F. and Comi, A. (2011). Measures for sustainable freight transport at urban scale: expected goals and tested results in Europe. Journal of Urban Planning and Development, DOI 10.1061/(ASCE)UP.1943-5444.0000052, American Society of Civil Engineers (ASCE).

[7] City Ports (2005). City Ports - project interim report. Emilia-Romagna, Bologna, Italy.

[8] CIVITAS (2011). CIVITAS - cleaner and better transport in cities - stands for CIty-VITAlity-Sustainability. www.civitas-initiative.eu.

[9] Taniguchi, E., Noritake, M., Yamada, T. and Izumitani, T. (1999). Optimal size and location planning of public logistics terminals. Transportation Research Part E 35, Elsevier Science, U.S.A.

[10] Browne, M., Sweet, M., Woodburn, A and Allen, J. (2005). Urban Freight Consolidation Centres - Final Report. Transport Studies Group, University of Westminster, United Kingdom.

[11] Marcucci, E. and Danielis, R. (2008). The potential demand for an urban freight consolidation centre. Transportation 35, Springer. 
[12] Munuzuri, J., Larraneta, J., Onieva, L., Cortes, P. (2005). Solutions applicable by local administrations for urban logistics improvement. Cities (22) 1, Elsevier.

[13] Van Duin, J. H. R. and Quak, H. J. (2007). City logistics: a chaos between research and policy making? A review. C. Brebbia (ed.), Urban Transport and the Environment in the $21^{\text {st }}$ Century, WitPress.

[14] Chow, J. Y. J., Yang, C. H., Regan, A. (2010). State-of-the art of freight forecast modeling: lessons learned and the road ahead. Transportation 37 (6), Springer Science+Business Media, LLC.

[15] Ogden, K. W. (1992). Urban Goods Movement. Ashgate, Hants, England.

[16] Hunt, J. D. and Stefan, K. J. (2007). Tour-based microsimulation of urban commercial movements. Transportation Research Part B 4, Elsevier.

[17] Wang, Q. and Holguin-Veras, J. (2009). Tour-based entropy maximization formulations of urban freight demand. Proceedings of the 88th Transportation Research Board Annual Meeting, Transportation Research Board, Washington DC, U.S.A.

[18] Oppenheim, N. (1994). Urban Travel Demand Modeling. John Wiley \& Son, New York.

[19] Routhier, J. L. and F. Toilier (2007). FRETURB V3, a policy oriented software of modelling urban goods movements. Proceedings of the 11th World Conference on Transport Research, Berkeley CA, U.S.A.

[20] Nuzzolo, A., Crisalli, U. and Comi, A. (2009). A delivery approach modeling for urban freight restocking. Proceedings of the $12^{\text {th }}$ International Conference on Travel Behaviour Research (IATBR), Jaipur, India.

[21] Russo, F. and Comi, A. (2002). Urban Freight Movement: a quantity attraction model. Urban Transport VIII: Urban Transport and the Environment in the $21^{\text {st }}$ Century, L. J. Sucharov, C. A. Brebbia and F. Benittez (eds.), DOI: 10.2495/UT020801, WitPress, Southampton, United Kingdom

[22] Russo, F. and Comi, A. (2003). Urban freight movements: quantity attraction and distribution models. Sustainable Planning \& Development, E. Beriatos, C. A. Brebbia, H. Coccossis and A. Hungolos (eds.), DOI: 10.2495/SPD030671, WitPress, Southampton, United Kingdom.

[23] Gonzalez-Feliu, J., Toilier, F. and Routhier, J.L. (2010). End-consumer goods movement generation in French medium urban areas. Procedia Social and Behavioral Sciences 2 (3), E. Taniguchi and R. G. Thompson (eds.), Elsevier Ltd.

[24] Cascetta, E. (2009). Transportation Systems Engineering: Model and Application, Springer.

[25] Filippi, F., Nuzzolo, A., Comi, A. and Delle Site, P. (2010). Ex-ante assessment of urban freight transport policies. Procedia - Social and Behavioral Sciences 2 (3), E. Taniguchi and R. G. Thompson (eds.), Elsevier Ltd.

[26] Ben-Akiva, M. and Lerman, S. R. (1985). Discrete Choice Analysis: Theory and Application to Travel Demand. The MIT Press, Cambridge, Massachusetts, U.S.A. 